\title{
Skeletal Stem Cell Characteristics in Iliac Crest Bone Graft and Clinical Implications in Fracture Non-Union Repair
}

Philipp Leucht, MD; Nury Yim, MD; Kenneth Egol, MD NYU Langone Orthopedic Hospital

\section{BACKGROUND}

- Autogenous bone grafting is an essential tool in the treatment of fracture non-unions

- Bone graft contains skeletal stem cells (SSC's) that differentiate into osteoblasts, an important step in fracture healing

- Relationship between the SSC composition of bone graft and clinical healing in fracture is non-union not fully understood

\section{OBJECTIVES}

- To determine if there is a relationship between patient characteristics and SSC composition in iliac crest bone graft

- To understand the clinical significance of SSC composition in the healing of fracture non-unions

\section{METHODS}

Human skeletal stem cell preparation:

- Bone marrow was aspirated from iliac crest from subjects undergoing repair of fracture non-unions

- Cells were prepared for flow cytometry analysis by staining for CD45- CD271+ cells. These markers have been used in previous studies for the identification of SSC

Radiographic analysis:

- Subjects were prospectively followed with serial radiographs to monitor fracture healing

- Radiographs were read by two independent observers, and time to union was determined by presence of bridging callus formation

Statistical analysis:

- Data are expressed as means \pm SEM and analyzed by unpaired two-tailed Student's t-test

\begin{tabular}{|c|c|c|c|c|}
\hline \multicolumn{7}{|c|}{ RESULTS } \\
\hline$\#$ & Male & Female & Overall & p \\
\hline Age & $48.72 \pm 14.98$ & $59.27 \pm 19.96$ & 51.33 & 0.039 \\
\hline BMI & $30.81 \pm 5.60$ & $28.37 \pm 6.31$ & 29.7 & 0.248 \\
\hline$\%$ \%cC & $0.162 \pm 0.113$ & $0.120 \pm 0.083$ & 0.145 & 0.211 \\
\hline $\begin{array}{c}\text { Time to } \\
\text { union } \\
\text { (months) }\end{array}$ & $5.37 \pm 2.73$ & $5.73 \pm 2.94$ & 5.52 & 0.750 \\
\hline
\end{tabular}

Table 1: Demographics data. No significant difference in BMI, percentage of SSCs, or time to radiographic union between males and females.

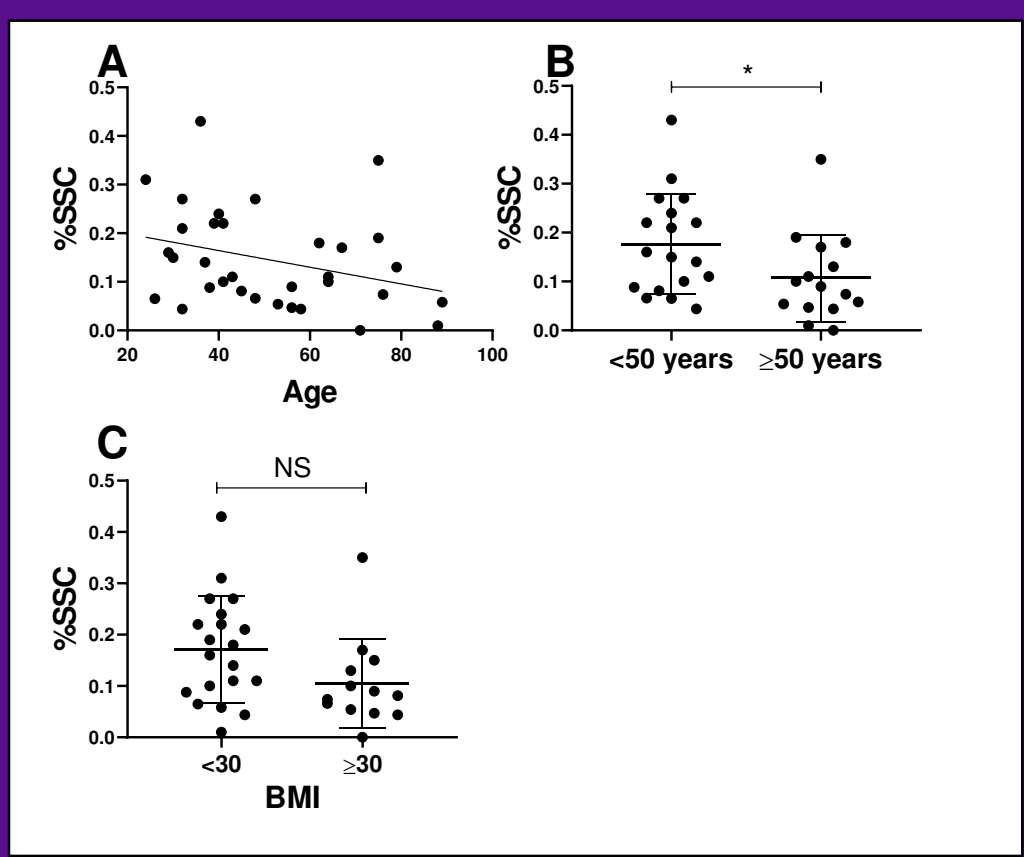

Figure 1: Skeletal stem cell composition affected by patient age. There was a negative correlation between age and percentage of CD271+ SSC in bone graft (A), although this did not reach significance $(p=0.0746)$ Subjects younger than 50 years old had a significantly higher percentage of SSCs in their bone marrow compared to those older than 50 years old $(B)(p=0.0497)$. Obese patients with a BMI greater than 30 had lower \%SSC in their bone graft, although this did not reach significance $(p=0.0633)$
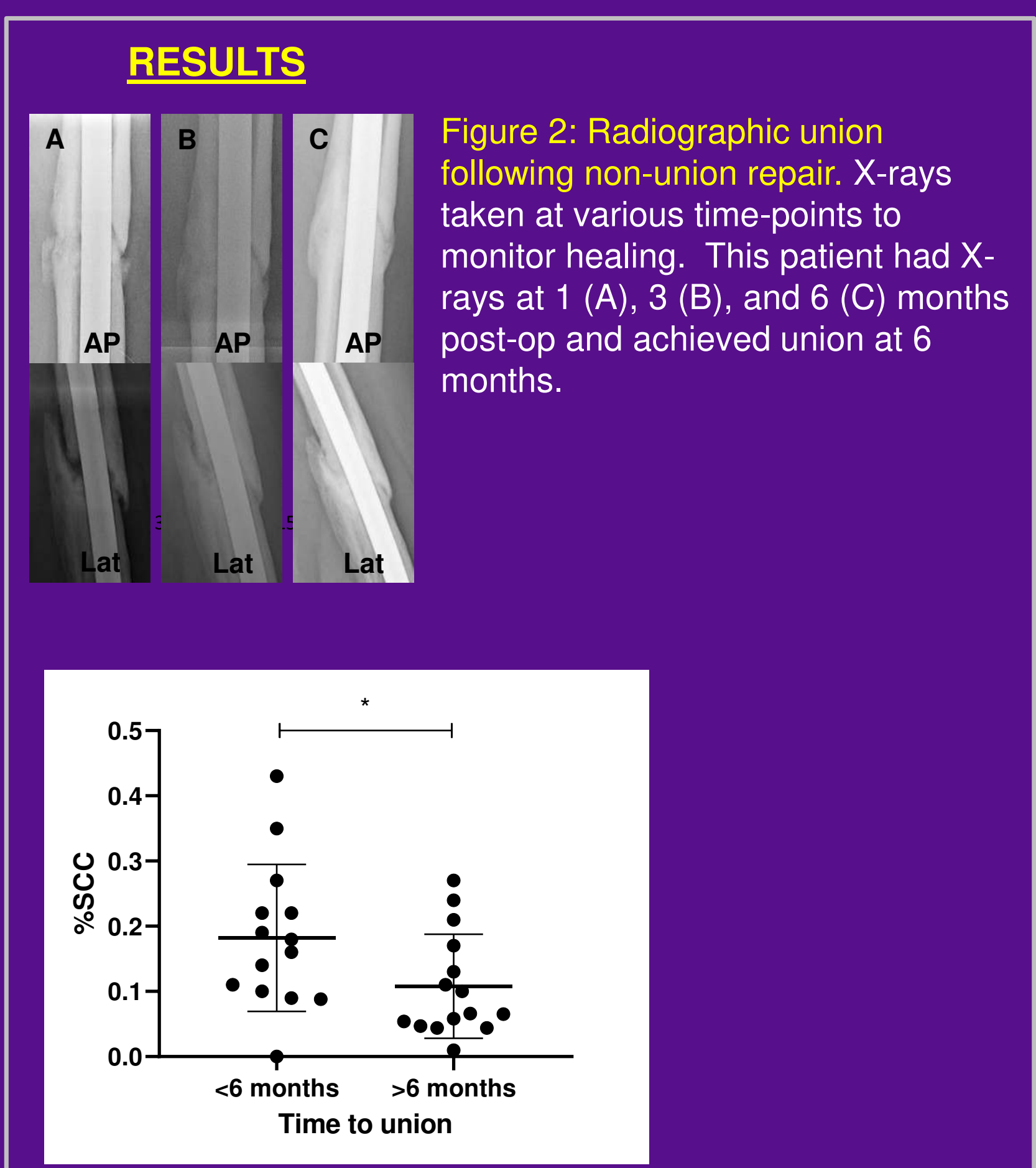

Figure 3: Time to union associated with \%SCC of bone graft. Patients who united by 6 months had a greater percentage of SSCs in their graft than those who those who took 6 months or longer to heal $(p=0.0495)$.

\section{CONCLUSIONS}

- There is a lower percentage of stem cells in bone graft in older patients than in younger patients

- Skeletal stem cell frequency in bone graft may be a predictor for time to union following non-union repair with autogenous bone graft 